\title{
The psychological impact and coping of Covid-19 pandemic among Arsi University students -Ethiopia
}

\author{
Dereje Adefris $^{1}$ (D) $\cdot$ Birhanu Moges ${ }^{1}$ \\ Accepted: 18 May 2021 / Published online: 12 June 2021 \\ (C) The Author(s), under exclusive licence to Springer Science+Business Media, LLC, part of Springer Nature 2021
}

\begin{abstract}
The foremost initiative of this investigation was to scrutinize the psychological influence of COVID-19 pandemic and the coping strategies of Arsi university students. Descriptive survey method was applied to investigate the intended variables. Data for this study was collected via an internet of 420 students (245 females and 175 males) from those whose email addresses were randomly accessed. Data was collect through questionnaires. Mean, standard deviation and t-test were used to analysis the collected data. The findings revealed that the psychological impacts of covid-19 on both male and female students were high. The results also showed that there was statistically significant difference between males and females in terms of every mean item. Therefore, it is recommended to engage actively in different activities, and relying on reliable sources of information, taking rests and the like are some of the mentioned coping strategies of the students. Finally, besides the transmitting of educational programs through TV, motivational speech, mass consultation/education through mass media like radio and television to reach those students who were dispersed to different parts of the country incorporates additional dimension of combating the psychological pressure of COVID-19.
\end{abstract}

Keywords Psychological impact · COVID-19 pandemic · University students · Arsi University · Coping of covid-19

\section{Introduction}

\section{Background of the Study}

It has been demarcated that COVID-19 pandemic originated in Wuhan - China then speedily feast across China to diverse countries of our planet since December 2019 (Cao et al., 2020; FMOH, 2020; Sood, 2020; Sun et al., 2020; Wang et al., 2020b). It had been in January 2020 that the WHO stated the outbreak of a new coronavirus disease, COVID-19 and in March 2020 with the assessment made COVID-19 could be regarded as a pandemic (WHO, 2020a, b). Hence, the eruption of COVID-19 has become the great source of psychological, economical, health threat to the population of the world in general and developing countries in particular. For

Dereje Adefris

ginbot21@gmail.com

Birhanu Moges

abirhanumoges@yahoo.com

1 Department of Psychology, College of Education and Behavioural Science, Arsi University, 2990 Adama, Ethiopia example, a research conducted in Kashmiri by Bhat et al. (2020) deliberated that the outburst of COVID-19 generates great burden to psychological resilience, economy and social life of people as well as a serious psychological influence to the Chinese people (Zhang et al., 2020). It has also created extensive psychological suffering in all countries of the world populations (UN, 2020). Furthermore, it was assumed that the influence of COVID-19 is social besides economic likewise psychological impacts (FMOH, 2020).

Furthermore, it was indicated that COVID-19 pandemic has been a severe risk to the wellbeing and the existence of patients in addition to the adjacent inhabitants assuming its short progress period, fast beginning, quick change, strong contagion and the like (Yoo, 2020). Consequently, inevitably the novel COVID-19 has become extra thought provoking to different educational institutes including higher education similarly to other organizations/industries too.

Many authors and scholars the effects of COVID-19 have reported it. Some of the effects of COVID-19 stated to be physical health, psychological well-being and the like. Accordingly, the preliminary assessment of students' project explained by Rakskul et al. (2020) regarding the psychological effects of COVID-19 illustrated that 34\% of people in a community had fright and anxiety of COVID-19 contagion. 
Similarly, the Department of Mental Health (2020) indicated that the anxiety screening survey made in Thailand within the April month of 2020 the respondents fingered out that they felt anxiety with wide-ranging degrees of which $7.42 \%$ slight anxiety, $75.89 \%$ modest anxiety and $16.01 \%$ intense anxiety. In other hand, the study on older adults showed Panchal et al. (2020) that $13 \%$ depressed, $22.6 \%$ worried for the period last days to months.

It is obvious that when different crises just like COVID-19 greatly disturb the lives of people's and communities hence extraordinary levels of tension are predictable to be extensively spread in the community (UN, 2020). In the connection to health, psychological, economical and for other similar thereat it has been paying great attention by the government of Ethiopia as well as the population of the country just corresponding to other nations of our planet that have been affected by the crises of COVID-19. Consequently, the government of Ethiopia has been taking different actions to elude the magnitude of COVID-19 pandemic besides to minimize the overall effect of the virus outbreaks in the country since the discovering of the first COVID-19 pandemic case in the country on March 13/2020 (WHO - Worldometer, 2020a, b).

In addition, the government of Ethiopia forfeited countless commitments to control the COVID-19 pandemic before it caused substantial damage to the populations (FMOH, 2020). Some of the measures taken to overcome the spread of the virus was closing schools, interrupting higher institute education, and soon after weeks closing all educational institutes in the country. Consequently, as per the letter written from the ministry of education dated on March 15/2020 with the refer number/ $\mathbf{7 P}$ Q $227 / 12$ to all governmental and private higher institutes within the country informed that to interrupt every face- to-face education until the next two weeks till new call had to be done to diminish the unfold of the pandemic (COVID-19) citing five infected cases found in Ethiopia (Hirut, 2020). Nevertheless, after 2 weeks the university students went back to their family as an action to cut back the unfolding of COVID-19 pandemic. Likewise, every school in Ethiopia had been closed on March 15/2020. Furthermore, the Ministry of Health of Ethiopia and the Ethiopian Health Institute in coordination with different stakeholders accomplish many preventive activities like identification, contact tracing, isolation and quarantine actions beyond promoting social distancing and sanitary measures (FMOH, 2020). However, the spread of COCID-19 pandemic has been amazingly increasing over the world as well as in Ethiopia. For instance, while we are ready to send this articles to the publisher (January 22/2021) the world total cases were $98,092,757$ while the total deaths were $2,100,452$, similarly in Ethiopia the total cases were 132,326 and 2057 deaths at a time (WHO-Worldometer, 2020b).

COVID-19 pandemic has been the central focus of attention all over the world, particularly its great influences on psychological, social and economic consequences (Cosic et al., 2020). It is supposed that many individuals in general and university students in particular are living with uncertainty over recent days. It is common phenomena to feel stressed or anxious during the period of COVID-19spreading entirely over the world, particularly difficult for individuals' previously experiencing feelings of anxiety or emotional distress (NAMI, 2020). Besides, the outbreak of COVID-19 pandemic can lead the community to feel fear and anxiety that can cause stressful situations or emotional problems (Maryland Department of Health, 2020). Particularly, UN (2020):2) described that "Emotional difficulties among children and adolescents are exacerbated by family stress, social isolation, with some facing increased abuse, disrupted education and uncertainty about their futures, occurring at critical points in their emotional development."

To sum up, the new COVID-19 pandemic has been great intimidation for all countries of the world in general and developing countries in particular. This is due to a weak economic and health system as well technology to overcome the impacts of COVID-19 pandemic. Subsequently, the impacts of COVID-19 pandemic anticipated to be complex in terms of health, social, economic and psychological areas. In connection, students who had been made to interrupt their university education and social life imposed to live with their family couldn't be expected to be free from the psychological impact of COVID-19 pandemic. Consequently, the current study focused on the psychological impact of COVID-19 pandemic on Arsi university students who has been interrupted their second semester education due to COVID-19 threat as well during the period of pandemic crises.

\section{Statement of the Problem}

Since a COVID-19 pandemic outburst does not have an explicit period demarcation, it can be one of the furthermost stressful types of catastrophe to combat with psychologically challenges due to the insecurity that it can generate (IDMH, 2020). Likewise, it is stated that numerous individuals are psychologically troubled for the reason that its instantaneous health influences of the virus and the consequences of physical separation; fear of infection, dying, and losing family members; physically distanced from loved ones and peers; losing or being at risk of losing their income and livelihoods, and deep uncertainty about the future are common sources of distress caused by COVID-19 pandemic crises (UN, 2020). Correspondingly, to regulate the spread of the virus, the government of Ethiopia has taken various measures; including closing all schools, higher institutes. Accordingly, Arsi university students were interrupted their education and college life due to the crises of COVID-19 since the mid of March 2020. Nevertheless, it was expected that no studies have been conducted on the psychological impact of 
COVID-19 pandemic on Arsi university students who have been interrupted their second semester education of 2019/ 2020 academic year with the action taken by the government of Ethiopia as a means to control the spread of the virus. As a result, we motivated and initiated to investigate the psychological impacts of COVID-19 and the coping strategies among Arsi university students.

\section{Objective of the Study}

This research was proposed to scrutinize the psychological impact of COVID-19 pandemic among students of Arsi University-Ethiopia. Besides, it was aimed to determine whether there is variation among male and female students in the responses to psychological impacts of COVID-19 pandemic. Accordingly, in line with objectives of the study the following leading questions and hypothesis were suggested.

1. What are the psychological impacts of COVID-19 pandemic among Arsi University students?

2. What are the coping strategies to psychological impacts of COVID-19 pandemic by Arsi University students?

H1: There is statistically significant variation between male and female of Arsi University students in the response to the psychological impact of COVID-19 pandemic.

\section{Methods of the Study}

Arsi university students were the subject who were participated in the study. An email-based, descriptive survey was conducted on the psychological impact of COVID-19 pandemic among Arsi university students in the months of May and June 2020. Students, those whose email address were accessed through different approaches considered as the representative sample of the study. Accordingly, 420 students were accessed and responded through email filling in the questionnaires correctly and appropriately (175 males and 245 females).

Among the numerous available information on different meanness items were set which thought to be able to measure the posed issue. Questionnaires were distributed among the students with email services to gather data from students regarding the psychological impact and the coping strategies of the influence of COVID-19 pandemic. Educators who have expertise in the area reviewed the questionnaire and their comments were convincing and constructive incorporated into the final approved data collection tools. Besides, some items that were used to investigate similar issues on different articles that were thought to be properly and easily able to measure the knowledge about COVID-19 pandemic as well as the psychological impacts on the students were selected and modified to have comprehensive data collection instruments.

In general, through internet or mail data was collected based on the willingness and the accessibility as well as the consent of the students who had contacted and were able to attach the questionnaires back. The research participants were assured that the data generated from them would be treated confidential. The reliability of the questionnaire was calculated through the SPSS 26 software package. It was found to be 0.878 (high) for 14 items (psychological impact items) using the reliability statistics of Cronbach's Alpha.

Furthermore, the collected data including the general awareness of COVID-19 (6 items), about the psychological effects of COVID-19 pandemic were 14 items; generally 20 items were feed into the SPSS 26 software package for ease analyzing and interpretation. This was done after each response of the respondents was checked for its completeness. Then each questionnaire was coded to provide opportunity for ease correction of mistakes if any error had been done during data feeding processes into the computer software.

The scale limit for the general awareness about COVID-19 pandemic was 0 for minimum mean and 1 for the maximum mean of the responses because yes was considered as 1 and no was considered as 0 for item $1-4$ while for the items 5 and 6 the inverse was true. For psychological impacts 5 Likert scale was used that imply; strongly disagree (1), disagree (2), so and so (3), agree (4) strongly agree (5). Therefore, the lowest mean of psychological impact was 1 and the highest mean was 5 while the average mean was 3 for each item. It was interpreted that if the mean of each item was above the mean (3) considered as high which has presented having significant psychological impact and if it was equal to or less than the average mean (3) the impact considered as less significant or normal reaction.

\section{Data Presentation and Results}

\section{The Psychological Impacts of COVIDe-19}

Here below the data for the psychological impact of COVID19 pandemic responses of the research participants presented. Besides, the presented data analysed and interpreted using the mean of each item. In short the average mean of the respondents if greater than the average (3) it was considered as high and if lower than or equal to it considered as lower or normal reaction as stated earlier on each of the psychological impact determinant items.

As indicated in the Table 1 above the female respondents demonstrated changes in appetite, energy, and activity levels greater than the average while the males less than the mean, as it is indicated in QQ2. On the other dimension, 
Table 1 Description statistics of the psychological impact of COVID-19 pandemic

\begin{tabular}{|c|c|c|c|c|c|}
\hline & Sex & $\mathrm{N}$ & Mean & Std. Deviation & Std. Error Mean \\
\hline \multirow[t]{2}{*}{ QQ1 } & Male & 175 & 2.40 & .491 & .037 \\
\hline & Female & 245 & 2.14 & .992 & .063 \\
\hline \multirow[t]{2}{*}{ QQ2 } & Male & 175 & 2.40 & 1.203 & .091 \\
\hline & Female & 245 & $3.29 * *$ & .453 & .029 \\
\hline \multirow[t]{2}{*}{ QQ3 } & Male & 175 & 2.00 & .897 & .068 \\
\hline & Female & 245 & 2.57 & 1.180 & .075 \\
\hline \multirow[t]{2}{*}{ QQ4 } & Male & 175 & 2.20 & .750 & .057 \\
\hline & Female & 245 & 1.57 & 1.052 & .067 \\
\hline \multirow[t]{2}{*}{ QQ5 } & Male & 175 & 2.40 & 1.501 & .113 \\
\hline & Female & 245 & 2.29 & 1.488 & .095 \\
\hline \multirow[t]{2}{*}{ QQ6 } & Male & 175 & $3.40 * *$ & 1.360 & .103 \\
\hline & Female & 245 & 2.57 & 1.052 & .067 \\
\hline \multirow[t]{2}{*}{ QQ7 } & Male & 175 & $4.00 * *$ & 1.269 & .096 \\
\hline & Female & 245 & $3.57 * *$ & .905 & .058 \\
\hline \multirow[t]{2}{*}{ QQ8 } & Male & 175 & 2.60 & 1.360 & .103 \\
\hline & Female & 245 & $4.29 * *$ & .701 & .045 \\
\hline \multirow[t]{2}{*}{ QQ9 } & Male & 175 & $3.20 * *$ & 1.170 & .088 \\
\hline & Female & 245 & $3.43 * *$ & 1.296 & .083 \\
\hline \multirow[t]{2}{*}{ QQ10 } & Male & 175 & $3.40 * *$ & 1.023 & .077 \\
\hline & Female & 245 & $3.14 * *$ & 1.460 & .093 \\
\hline \multirow[t]{2}{*}{ QQ11 } & Male & 175 & 2.20 & 1.474 & .111 \\
\hline & Female & 245 & 2.71 & 1.032 & .066 \\
\hline \multirow[t]{2}{*}{ QQ12 } & Male & 175 & 2.20 & 1.474 & .111 \\
\hline & Female & 245 & 1.29 & .453 & .029 \\
\hline \multirow[t]{2}{*}{ QQ13 } & Male & 175 & $3.20 * *$ & 1.605 & .121 \\
\hline & Female & 245 & $4.00 * *$ & .928 & .059 \\
\hline \multirow[t]{2}{*}{ QQ14 } & Male & 175 & 2.40 & 1.501 & .113 \\
\hline & Female & 245 & 1.71 & 1.163 & .074 \\
\hline
\end{tabular}

Remark: - ** the mean of the responses is above the average (high psychological impacts on the determinants).

as it is indicated by item QQ6 male students' demonstrated stronger fear of contacting to COVID-19 virus whereas the females students less than the average. Both the male and the female respondents feel confusion and uncertainty about the future (QQ7) particularly male respondents strongly demotivated for the future time of continuing education (QQ8) while females not. On the other hand, both male and female respondents ascertained that they fear and worry about their own health and the health of their loved ones (QQ9). Similarly, both male and female respondents demonstrated that sadness, anger or frustration because their friends or loved ones have unfounded fears of contracting the disease from contact with them, even though they have been determined not to be contagious (QQ10). In addition, both the male and the female respondents particularly males demonstrated that they were bored staying in the home for a longer period of time (QQ13).

\section{Comparison of the Psychological Impact of COVID-19 among Male and Female Respondents}

Here below the comparison of mean response between male and female students presented. The t-test was used to compare the mean of the males and females responses on the psychological impacts of COVID-19 pandemic as shown in Table 2 below. The items with below the average (3) indicated in Table 2 were excluded from executing here since the mean of the responses were below or equal to the average mean (3), it was considered as lower or normal psychological reaction to COVID-19 pandemic or they were sought to be nonpsychological impact determinant items.

The t-test results displayed in Table 2 confirms the existence of statistically significant differences between male and female respondents experiencing different psychological phenomena as specified in Table 1 on every item. The female respondents exhibited significantly higher variation in some areas (psychological impact determinant items) than males' respondents. Accordingly, the female respondents demonstrated statistically significant variation than male in the area of changes in appetite, energy and activity levels $(\mathrm{t}=10.528, P=.000)$; demotivated for the future time of continuing education $(\mathrm{t}=16.563, \mathrm{P}=.000)$; fear and worry about their own health and the health of their loved ones $(\mathrm{t}=1.855, P=064)$ and boring staying in the home for longer period of time $(\mathrm{t}=6.442, P=.000)$ than male students.

On the other dimensions', male respondents exhibited higher variation than female respondents in some other issues (determinants). In this regards, the male respondents demonstrated statistically significant variation than female in the area of fear of contracting to COVID-19 virus $(\mathrm{t}=7.035, P=.000)$; feel confusion and uncertainty about future $(\mathrm{t}=4.041$, $\mathrm{P}=.000$ ) and sadness, anger or frustration because of their friends or loved ones have unfounded fears of contracting the disease from contact with them, even though they have been determined not to be contagious $(\mathrm{t}=2.005, P=.046)$.

\section{Psychological Impact and Strategies to Overcome of COVID-19 Open-Ended Responses}

The first open-ended question requests the research participants to explain what they think of the psychological effects of COVID-19. Accordingly, what the majority of the research participants were cited as indicated as the followings;

- Strong feeling of depression, stress, unhappiness due to staying at home for such an extended time without any task

- Weak social interaction/loneliness results in depression

- Not taking care of the self 
Table 2 Inferential statistics by sex through independent Samples T-Test

\begin{tabular}{|c|c|c|c|c|c|c|c|c|c|c|}
\hline & & \multicolumn{2}{|c|}{$\begin{array}{l}\text { Levene's Test for Equality of } \\
\text { Variances }\end{array}$} & \multicolumn{7}{|c|}{ t-test for Equality of Means } \\
\hline & & \multirow[t]{2}{*}{$\mathrm{F}$} & \multirow[t]{2}{*}{ Sig. } & \multirow[t]{2}{*}{$\mathrm{t}$} & \multirow[t]{2}{*}{ df } & \multirow[t]{2}{*}{ Sig. (2-tailed) } & \multirow{2}{*}{$\begin{array}{l}\text { Mean } \\
\text { Difference }\end{array}$} & \multirow{2}{*}{$\begin{array}{l}\text { Std. Error } \\
\text { Difference }\end{array}$} & \multicolumn{2}{|c|}{$95 \% \mathrm{CID}$} \\
\hline & & & & & & & & & Lower & Upper \\
\hline \multirow[t]{2}{*}{ QQ2 } & Equal variances assumed & 518.961 & .000 & -10.528 & 418 & .000 & -.886 & .084 & -1.051 & -.720 \\
\hline & Equal variances not assumed & & & -9.279 & 209.422 & .000 & -.886 & .095 & -1.074 & -.698 \\
\hline \multirow[t]{2}{*}{ QQ6 } & Equal variances assumed & 64.598 & .000 & 7.035 & 418 & .000 & .829 & .118 & .597 & 1.060 \\
\hline & Equal variances not assumed & & & 6.745 & 313.582 & .000 & .829 & .123 & .587 & 1.070 \\
\hline \multirow[t]{2}{*}{ QQ7 } & Equal variances assumed & 95.333 & .000 & 4.041 & 418 & .000 & .429 & .106 & .220 & .637 \\
\hline & Equal variances not assumed & & & 3.827 & 295.731 & .000 & .429 & .112 & .208 & .649 \\
\hline \multirow[t]{2}{*}{ QQ8 } & Equal variances assumed & 84.208 & .000 & -16.563 & 418 & .000 & -1.686 & .102 & -1.886 & -1.486 \\
\hline & Equal variances not assumed & & & -15.028 & 240.158 & .000 & -1.686 & .112 & -1.907 & -1.465 \\
\hline \multirow[t]{2}{*}{ QQ9 } & Equal variances assumed & 15.895 & .000 & -1.855 & 418 & .064 & -.229 & .123 & -.471 & .014 \\
\hline & Equal variances not assumed & & & -1.887 & 395.938 & .060 & -.229 & .121 & -.467 & .010 \\
\hline \multirow[t]{2}{*}{ QQ10 } & Equal variances assumed & 36.359 & .000 & 2.005 & 418 & .046 & .257 & .128 & .005 & .509 \\
\hline & Equal variances not assumed & & & 2.123 & 417.861 & .034 & .257 & .121 & .019 & .495 \\
\hline \multirow[t]{2}{*}{ QQ13 } & Equal variances assumed & 125.923 & .000 & -6.442 & 418 & .000 & -.800 & .124 & -1.044 & -.556 \\
\hline & Equal variances not assumed & & & -5.926 & 256.579 & .000 & -.800 & .135 & -1.066 & -.534 \\
\hline
\end{tabular}

The second open-ended question requests the research participants to explain what they think of the strategies to minimize the psychological effects of COVID-19 pandemic. Accordingly, the majority of the respondents mentioned the following strategies to reduce the psychological impacts of COVID-19 pandemic;

- Physical-exercise

- Reading different of books

- Interacting with family

- Believing in God and praying

- Manage the self by taking proper rest,

- Choosing and consuming trusted source of information,

- Using different entertainment TV channels,

- Using internet sites in most appropriate, effective and efficient ways

To sum up, what the research participants revealed about the psychological impact of COVID-19 and the strategies to overcoming its impact were generalized as indicated above. Different activities and relying on reliable sources of information, taking rests and the like are some of the mentioned coping strategies of the students.

\section{Discussion}

The psychological pressure of COVID-19 on the Arsi university students was found to be high. In general, different research findings and literatures indicated that the psychological impact of COVID-19 were high and affects physical and psychological wellbeing of the people (UN, 2020; Wang et al., 2020a; Salman et al., 2020; Department of Health, 2020; Carrying community, 2020. Accordingly, a wide range of thoughts, feelings and reactions could be common symptoms to coronavirus information and responses with different degrees of consequence such as fear, anxiety, worry, panic, feeling of helplessness, social withdrawal and the like (McGuire et al., 2020; University of health services Tang Center, 2020; Wilson, 2020).

The stated hypothesis of the research deals with the existence of a significant difference of psychological impact of COVID-19 pandemic between male and female students of Arsi University. In this regard, independent samples t-test indicated that there was significance mean differences between male and female students by all the determinants of psychological impacts of COVID-19 pandemic of which in 3 items males mean surpasses the mean average response of females conversely with 4 items female students by pass male students as indicated under Tables 1 and 2. Likewise, the findings of UN (2020) and Wang, et al. (2020b) were similar to the findings of the current study.

Regarding the strategies to overcome the psychological impacts of COVID-19 specified that physical-exercise, reading different of books, interacting with family's, believing in God and praying, changing lifestyle, manage the self by taking proper rest, choosing consuming trusted source of information, using different entertainment TV channels, using internet sites in most appropriate, effective and efficient ways. Similarly, the most frequent 
coping strategy adapted to COVID-19 crises are religious/ spiritual coping, acceptance, self-distraction and active coping (Salman et al., 2020). Likewise, social interaction with individuals to be trusted, avoid excessive exposure to media coverage of COVID-19 pandemic, etc. (Maryland Department of Health, 2020; NAMI, 2020).

\section{Conclusion and Recommendation}

It is supposed that COVID-19 pandemic has influenced all countries; everyone at all ages levels of our planet. Nevertheless, the current study focused among Arsi University students' of which one of the higher institute found in Ethiopia concerning the psychological impact of COVID19 pandemic outbreak and the coping strategies. The results of the study discovered that almost the majority of the research participants had revealed that the psychological impacts of COVID-19 pandemic on both male and female students were high. This was associated with sudden and high contagious characteristics of COVID-19 pandemic that causes people with anxiety, depression and other psychological impacts (Wang, et al., 2020b). Lastly, it was discovered that there was statistically significant variation between male and female students on the psychological impact determinant items of COVID-19 pandemic.

As it was mentioned and emphasized by the research participants, it is recommended that engaging in physicalexercise, reading different books, interacting with families, praying to their God, changing lifestyle, taking proper rest, choosing trusted source of information, using different entertainment TV channels, using internet sites in appropriate and effective as well as in an efficient way. Finally, besides the transmitting of educational programs through TV, motivational speech, and mass consultation/ education through mass media (radio and television) to reach those students who have been disseminated to different parts of the country excludes an additional measurement of the recommendation.

\section{Recommendations for Future Study}

What are the post COVID-19 psychosocial effects on the university students in Ethiopia? What are the psychological impacts of COVID-19 on late childhood in Ethiopia? These are the two research topics that will be recommended for future study.

Acknowledgements We really appreciate and thank every student who had been taken part willingly to provide the necessary data for this study. Particularly, our thanks and appreciations are unique to student Rediet Tamiru, who paid great scarifies to contact student respondents for this research to come to the reality. Rediet thanks you once again for your great endeavors.

Availability of Data and Material Yes the data is available with me.

Code Availability We used SPSS software for data analysis, the analysis out pit clearly indicated in the data analysis part and presented in the form of tables.

Authors' Contribution Assistant professor and associate professor respectively of Arsis University. Conducting researches besides teaching, advising thesis for master students, articles reviewers for different journals.

\section{Declarations}

Ethical Approval Waived, since the research participates were above 18 years, and guaranteed that the data generated of them would be confidential.

Consents to Participate With the heading of the questionnaire it was asked for their willingness and consent to fill in the questionnaire and send back through email.

Consent for Publication We guarantee that it is free to publish and to sell or else to take any necessary actions what the publisher thinks ethical and appropriate.

Conflict of Interest There is no potential conflict of interest.

\section{References}

Bhat, B., Khan, S., Manzoor, S, Niyaz, A, Tak, H., Anees, S., Gull, S., \& Ahmad, I., (2020). A study on impact of COVID-19 lockdown on psychological health, economy and social life of people in Kashmir. International Journal of Science and Healthcare Research, 5(2), 3646. Retrieved from https://ijshr.com/IJSHR_Vol.5_Issue.2_ April2020/IJSHR005.pdf

Cao, W., Fanga, Z., Houc, G., Hana, M., Xua, X., Donga, J., \& Zhenga, J. (2020). The psychological impact of the COVID-19 epidemic on college students in China. Psychiatry Research, 287(112934), 1-5. https://doi.org/10.1016/j.psychres.2020.112934.

Carrying community. (2020). COVID-19 psychological wellness guide: anxiety management, Version 3, 4/20/20. Retrieved from https:// med.emory.edu/departments/psychiatry/_documents/tips.anxiety1. pdf

Cosic, K., Popovic, S., Šarlija, M., \& Kesedžic, I. (2020). Impact of human disasters and COVID-19 pandemic on mental health: Potential of digital psychiatry. Psychiatria Danubina, 32(1), 2531. https://doi.org/10.24869/psyd.2020.25.

FMOH. (2020). National comprehensive COVID19 management handbook. Federal ministry of health.

Hirut, Woldemariam. (2020). Ministry of science and higher education, march 15/2020 Addis Ababa.

IDMH. (2020). Tips for community members COVID-19: Managing stress in this anxious time. Institute for Disaster Mental Health. State University of New York at new Paltz.

Maryland Department of Health. (2020). Coronavirus Disease 2019 (COVID-19): Frequently asked questions about mental health. Retrieved from https://www.samhsa.gov/disaster-preparedness 
McGuire, T., Rowe, J., \& Herr, C. (2020). Psychosocial correlates of outbreak response activities: A supplemental literature report. Washington State Department of Health.

NAMI. (2020). COVID-19 (coronavirus) information and resources. The National Alliance on Mental Illness. Retrieved from www.nami.org/ COVID-19

Panchal, N., Kamal, R., Orgera, K., Cox, C., \& Garfield, R. (2020). The implications of COVID-19 for mental health and substance use. KFF.

Rakskul, A., Indech, W., Promjad, N., Cheuktong, S., \& Leeteera, T. (2020). The report project of mental health promotion and mental disorder prevention. Unpublished report of master graduate students. Thammasat University.

Salman, M., et al. (2020). Psychological impact of COVID-19 on Pakistani University students and how they are coping. medRxiv preprint. https://doi.org/10.1101/2020.05.21.20108647.

Sood, S. (2020). Psychological effects of the coronavirus disease-2019 pandemic. RHiME, 7, 23-26.

Sun, P., et al. (2020). A qualitative study on the psychological experience of caregivers of COVID-19 patients. American Journal of Infection Control, 48, 592-598.

UN. (2020). Policy brief: COVID-19 and the need for action on mental health. United Nations.

University of Health Services Tang Center (2020). Managing fears and anxiety around coronavirus. Retrieved from www.uhs.berkeley.edu/ coronavirus

Wang, J., Wang, J. \& Yang, G. (2020a). The psychological impact of COVID-19 on Chinese individuals. Yonsei Med Journal, 61(5):438440. Doi.org/https://doi.org/10.3349/ymj.2020.61.5.438.

Wang, Y., Di, Y., Ye, J. \& Wei, W. (2020b). Study on the public psychological states and its related factors during the outbreak of coronavirus disease 2019 (COVID-19) in some regions of China. Psychology, Health \& Medicine. Retrieved from https://doi.org/10. 1080/13548506.2020.1746817

WHO - Worldometer. (2020a). Coronavirus Cases In Ethiopia. Retrieved from https://www.worldometers.info/coronavirus/country/ethiopia/

WHO - Worldometer. (2020b). Worldometer's COVID-19 data. Retrieved from https://www.worldometers.info/coronavirus/ (January 22/2021).

WHO. (2020a). Healthy at home-Mental health. https://www.who.int/ newsroom/ campaigns/connecting-the-world-to-combatcoronavirus/healthyathome/healthyathome-mental-health (accessed May 18, 2020).

WHO. (2020b). Mental health and psychosocial considerations during the COVID-19 outbreak. World Health Organization. With WHO reference number: WHO/2019-nCoV/Mental Health/2020.1.

Wilson, S. (2020). Managing fears and anxiety around the coronavirus (COVID-19). CAMHS (Harvard University Counseling and Mental Health Services). Retrieved from www.harvard.edu/coronavirus

Yoo, J. H. (2020). The fight against the 2019-nCoV outbreak: An arduous march has just begun. Journal of Korean Medical Science, 35(4), 1 3. https://doi.org/10.3346/jkms.2020.35.e56.

Zhang, J., Wu, W., Zhao, X. \& Zhang, W. (2020). Recommended psychological crisis intervention response to the 2019 novel coronavirus pneumonia outbreak in China: A model of West China hospital. Precision Clinical Medicine, 3(1), 3-8. Doi.org/https://doi.org/10. 1093/pcmedi/pbaa006.

Publisher's Note Springer Nature remains neutral with regard to jurisdictional claims in published maps and institutional affiliations. 